\title{
EFFECTIVE TREATMENT WITH DEXMEDETOMIDINE FOR SEVERE BRONCHOSPASM AFTER PLEURODESIS PROCEDURE
}

\author{
Pereira Esmoriz L., Fernandez Pérez A.B., Tolosa Morales F., Amador I., \\ Sanchez Navas Parejo M., Bethencourt Rocha R.J. \\ Hospital Universitario Nuestra Señora de la Candelaria, Dept of Anaesthesiology, Santa Cruz de Tenerife, Spain
}

\begin{abstract}
Background: The role of dexmedetomidine solving a case of postoperative bronchospasm in a patient who underwent pleurodesis.
\end{abstract}

Case report: A 63 years old male and $75 \mathrm{Kg}$ patient was programed for pleuroscopy and pleurodesis under sedation. Throughout the procedure, patient suffered cough and mild subcutaneous thoracic emphysema. Previous diseases: right pulmonary effusion and upper lobe lung neoplasia. Allergy to metamizol. Usual treatment with inhaled foster. After 2 hours at the PACU, sudden increase of subcutaneous emphysema radiating to neck and face with impaired fonation and cough started. Pleural drainage was repositioned and severe bronchospasm appeared. $0.4 \mathrm{mg}$ IM Adrenaline, $10 \mathrm{mg}$ IV ketamine and 1,5g IV magnesium was given and placed a 2 nd drainage. A continous intravenous infusion of dexmedetomidine $0.5-1 \mathrm{mcg} / \mathrm{Kg} / \mathrm{h}$ was used, disappearing dyspnea.

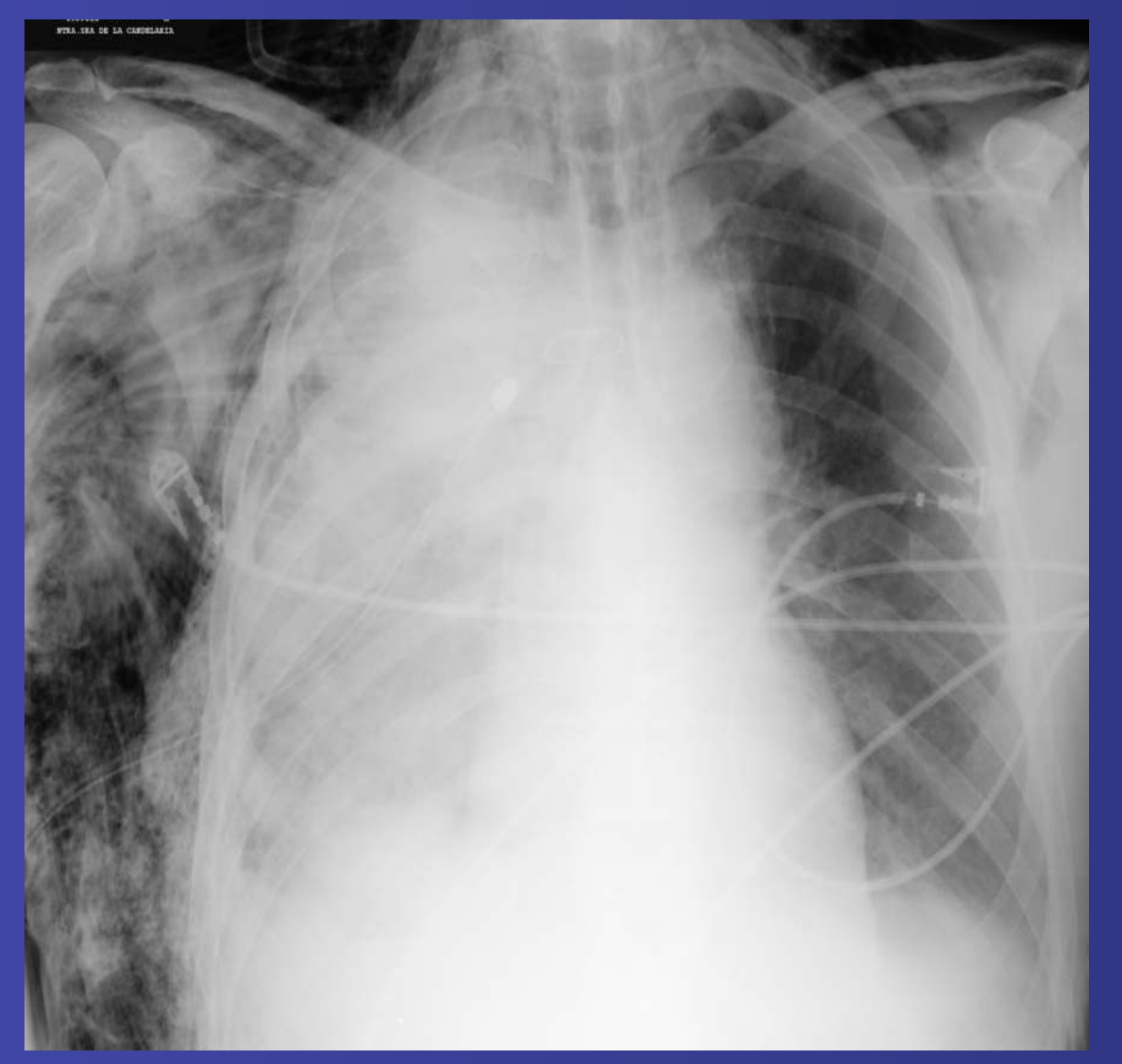

Discussion: In vitro studies of human and animal bronchial tissue indicate that alpha2-adrenoceptor stimulation lead to smooth muscle relaxation. This effect seems to be mediated via a presynaptic mechanism ${ }^{1}$. Dexmedetomidine has been approved for clinical use for sedation of patients who need mechanical ventilation in the intensive care unit. Alpha2-Adrenoceptor stimulation with intravenous dexmedetomidine blocked histamine-induced bronchoconstriction in dogs ${ }^{2}$. Therefore, dexmedetomidine might be beneficial to decrease airway reactivity in patients with chronic obstructive pulmonary disease or asthma ${ }^{3}$.

Learning points: Intravenous administration of dexmedetomidine in low doses is an effective treatment to attenuate bronchospasm. Dexmedetomidine could have bronchoprotective effects and might have additional advantages for patients with asthma or chronic obstructive pulmonary disease.

1. Lou YP, Franco-Cereceda A, Lundberg JM: Variable alpha2-adrenoceptor-mediated inhibition of bronchoconstriction and peptide release upon activation of pulmonary afferents. Eur J Pharmacol 1992; 210: 173-81.

2. Groeben H1, Mitzner W, Brown RH. Effects of the alpha2-adrenoceptor agonist dexmedetomidine on bronchoconstriction in dogs. Anesthesiology. 2004 Feb;100(2):359-63. 3.Tian X1, Li H, Ji Z, Zhao S, Sun M. Application of dexmedetomidine sedation in treatment of continuous state of asthma, a case report. Zhonghua Wei Zhong Bing Ji Jiu Yi Xue. 2014 Aug;26(8):598. doi: 10.3760/cma. j. issn. 